\title{
REUSE OF THE INDUSTRIAL HERITAGE OF MILAN: CULTURAL SETTLEMENT IN BOVISA
}

\author{
A. VILLACAMPA \& M. POLI \\ Politecnico di Milano, Italy.
}

\begin{abstract}
After the deindustrialization process of Europe, many buildings and complexes were abandoned and their activities were moved out of the cities due to the growth of urban centres. One of those locations is Bovisa in the North of Milan (Italy), in which old structures of former factories are standing near contemporary buildings. Furthermore, as a common characteristic of those industrial urban areas, the price of the land is one of the factors that affect their industrial archaeology preservation and its future development. The main goal of this research is to define a gentrification strategy that can be sustainable for the urban growth and social development of the area. Based on this, the analysis will be presented in two parts: (1) the adaptive reuse of these buildings has been considered as a motor for sustainability and culture in Bovisa. (2) A case study: an architectural project specifically designed for one of these industrial buildings as an example of reuse and sustainability. Keywords: Adaptive reuse, cultural planning, cultural settlement, deindustrialization, gentrification, industrial heritage, urban sustainability.
\end{abstract}

\section{INTRODUCTION}

Since the end of the 1980s, an important process of urban regeneration has taken place in the Milano-Bovisa area. In this transformation, Politecnico di Milano is still one of the main factors contributing to the development of the area with two campuses for architecture, engineering and design. The whole development was not a single project but a conjunction of progressive phases, which has not yet been completed. The Bovisa district can be described as an ex-industrial area, in the Northwest outskirts of Milan (Italy), where only a few houses where located until 1880. The development of Bovisa began when several chemical companies located their factories on the area, transforming it into one of the main hubs of the Italian industrial chemistry sector (Fig. 1). In the beginning of the 1900s, the workshops and warehouses of Teatro alla Scala were also established for set design and costume production. Furthermore, the setting up of the regional railway company (Ferrovie Nord) became an asset for the development of electromechanical industries as well. This way, the Bovisa factories reached an important level of production. Nevertheless, since the 1970s, the industrial reconversion process started and numerous factories were closed. Between 1974 and 1985, industrial workers in the Milanese factories decreased from 12,000 to 6,000. However, it was during these years that the idea of a new Politecnico campus in Bovisa emerged to be affirmed by the Milan Municipality in 1987.

The good connections with the Malpensa Airport, the main train stations, the city centre and with the new Fairground Exhibition area enforced the position and the role of Bovisa as one of the strategic areas of Milan. The Architecture Faculty of Politecnico di Milano was officially opened in Bovisa in 1989, at the ex-FBM industrial hangar. In 1994, the plants of ex Ceretti \& Tafani (cable production) in via Durando were renovated to host the Architecture and Design Faculties. Nowadays, the campuses are well integrated in the neighbourhood, thanks to the characteristics and services of the university buildings where about 6,500 students and 300 employees work every day [1]. Inside the precedent context, the development of a gentrification strategy that can be sustainable for the urban, cultural and social growth of the area has developed supported by cultural planning, urban development and statistics tools to analyse the diversity of factors of Bovisa. For this analysis a 


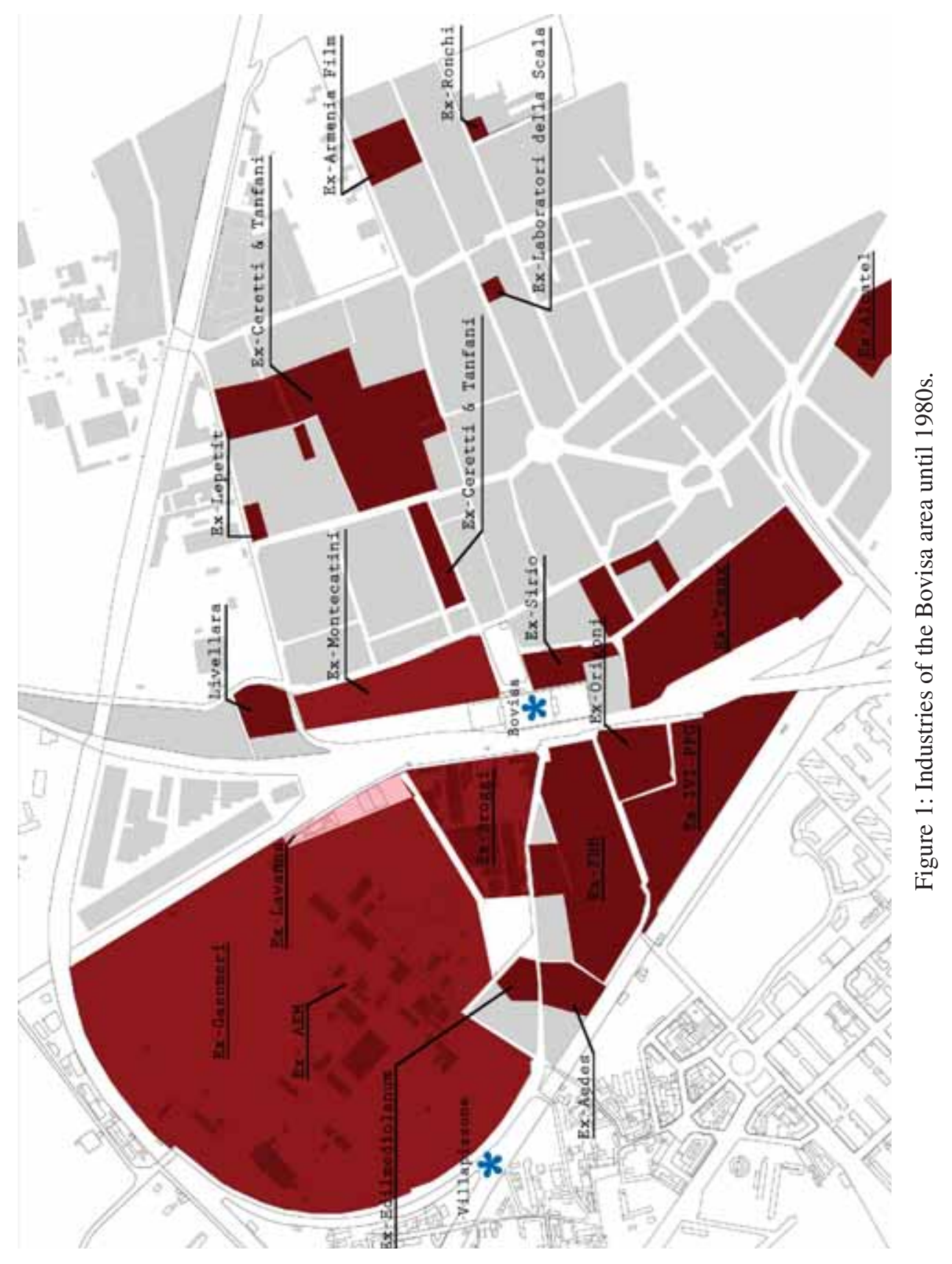


whole database - but not closed - has been evaluated that measures variables such as the amount of industrial buildings and their state of conservation; the existing and possible future green areas; the soil pollution levels for each former industry location according to the kind of activity developed; the location itself and the current uses among others (Fig. 2) [2].

A specific example for the implementation of an adaptive reuse in Bovisa with these characteristics is the heterogeneous group of buildings at Via Privata Stefano Siccoli at the Northwestern part of the area. The proposal for this whole complex was to transform and adapt to become the new headquarters for the Milanese cultural association esterni. Despite the aim of using recycled cargo containers and other industrial components as a construction element for a sustainable architectural project, the decontamination of a deeply polluted soil becomes a priority after years of highly uncontrolled damaging industrial activity.

In conclusion, the aim of the project is to consider the adaptive reuse of these buildings as a motor for sustainability and cultural development at a unique context in the city of Milan: the transformation would generate a whole sustainable district dedicated to arts, culture, education and research that will integrate the existent neighbours.

\section{REUSE AND SUSTAINABLE GENTRIFICATION}

The city of Milan, like most western cities, has gone through important economic, social and cultural changes. The great industrial zones that surrounded the big urban areas up to the end of the 20th century - with small and medium sized companies that complemented their production - had faced the repercussion of technological progress and market needs and have moved to other locations. Consequently, the areas that have been freed from this type of use are nowadays placed in semicentral parts of the city, generally close to the public transport network. In this new context, the economy of Milan is still based on business sectors like fashion, chemical production or industrial design. Moreover, the presence of different ethnic groups in the city generates the need to face cultural changes. In the city of Milan, the structure of the cultural and artistic production at an international level offers many opportunities provided by new entrepreneurs focused on young and contemporary artists. These business operators often work in associations or as truly independent businesses. They welcome the strong potential of young people's ideas without, however, having the power to give form to these experiences and take benefit of the added value that could be derived from integrity in a network. In the context of a cultural reuse, there are several existing companies in Milan that develop cultural projects on different levels with similar characteristics. Some examples are La Fabbrica del Vapore, Fondazione Arnaldo Pomodoro, The HUB, Lambretto Art Project or Assab One among others. All these examples are located in buildings originated by industrial uses that have been adapted to a cultural programme. In comparison to this dispersion of locations, Bovisa offers a high concentration of industrial architecture and the opportunity for a homogeneous reuse of the land with the new cultural activities that have been slowly introduced. This fact could lead to a large-scale cultural area and/or educational settlement where arts, education, research, crafts and culture can be developed and still be part of the urban fabric. In a wider range, this can be understood as a model for sustainability and urban development, thanks to the reuse of the industrial heritage and the introduction of green areas, urban orchards and eco-design practices. The main goal of this gentrification process is to be respectful with the existent inhabitants of the Bovisa area improving their life quality and protection against speculation. To achieve this, it is important to plan the area according to the needs of present and future communities: traditional inhabitants, immigrants, artists, visitors, students, researchers, designers or architects. 


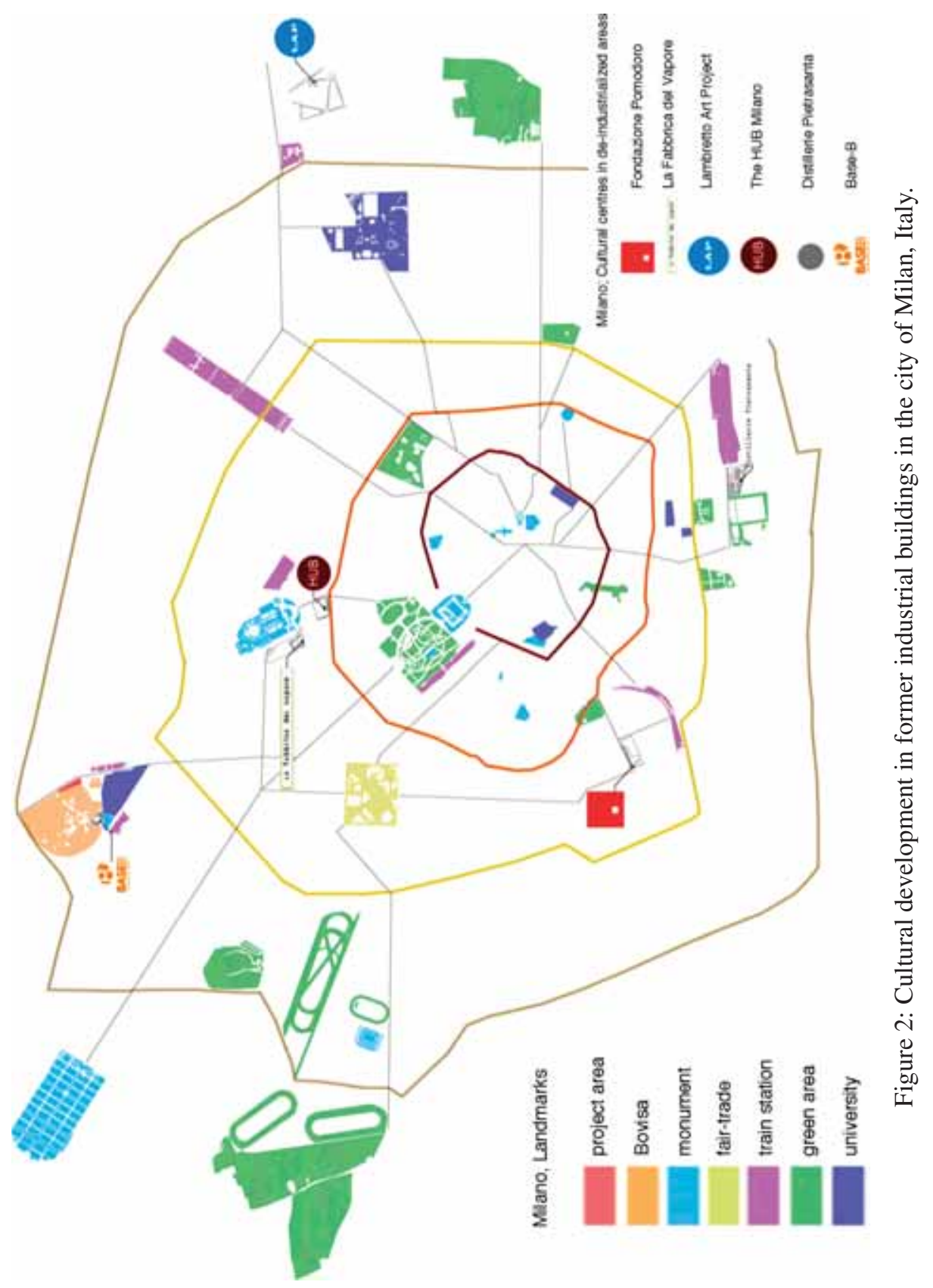




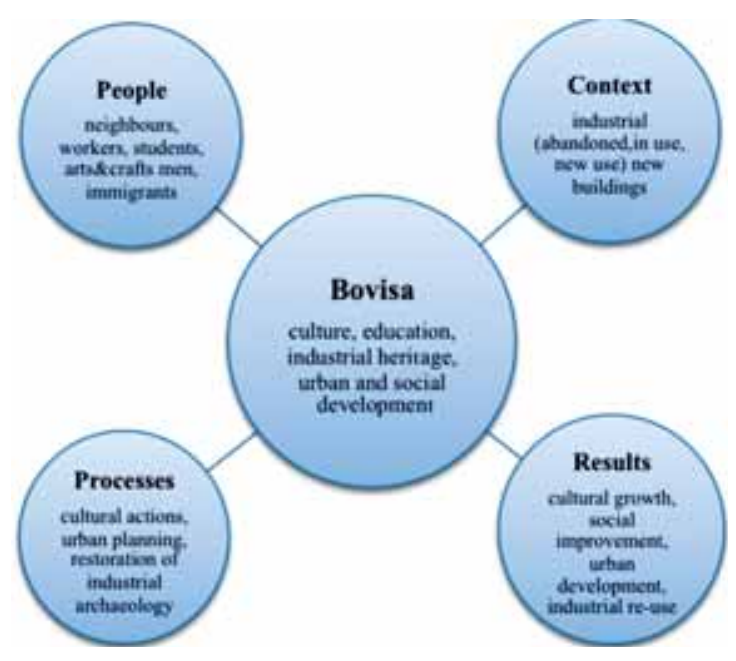

Figure 3: Project layers.

The recovery of ancient agricultural areas like the red berries orchards and the introduction of green architecture can be taken as an asset for the cleaning of the chemically polluted soil that affects many areas in Bovisa.

The implementation of new activities and users will be a slow process that will take part according to many factors like the state of conservation of each building, pollution levels, price of the land, requirements and needs of the client and the proximity to the public transport system among others.

Moreover, in the area of Bovisa, there exist some remarkable cultural and educational institutions like Politecnico di Milano and Triennale Bovisa. In addition, the ongoing master plan by Euromilano, called Nuova Bovisa [3], will impulse the educational and business activities on the area.

As has been pointed out before, the population of the Bovisa neighbourhood nowadays varies from students and artists to traditional inhabitants and immigrants who share their everyday life in an industrial context in which the price and the use of the land is in constant change due to the state of urban redesign processes required by the municipality and the public administrations. At the same time, the population of Bovisa changes depending on the day of the week, the time of the day or the events and exhibitions that are temporarily shown at the cultural and art locations. However, the urban development of Bovisa is based on classical urban planning and architecture principles, although the regeneration of uses has to be intended as a cultural planning strategy adapted for a large-scale location.

This cultural planning approach requires close interaction with a given context. It starts with a general enquiry concerning the geography of the place, demography and social history. Furthering the research, a closer investigation is devoted to what issues are of relevance to the place and can be tackled through the thinking and action of contemporary cultural events. At this point, education and marketing plans are devised. Education is seen as a built-in part of the concept, and community groups are invited to contribute to parts of the project. In terms of marketing, the mechanisms for reaching different groups, in the immediate surroundings and further afield have to be put in place.

The part of the research dedicated to analyse practice has to be carried out by looking closely at the underpinning elements of every contemporary cultural planning project. Here we should go back to the basics and list every detail relating to people, contexts, processes and results in project marketing. Each of these layers is subdivided into a number of components and summarized in Fig. 3 [4]. 


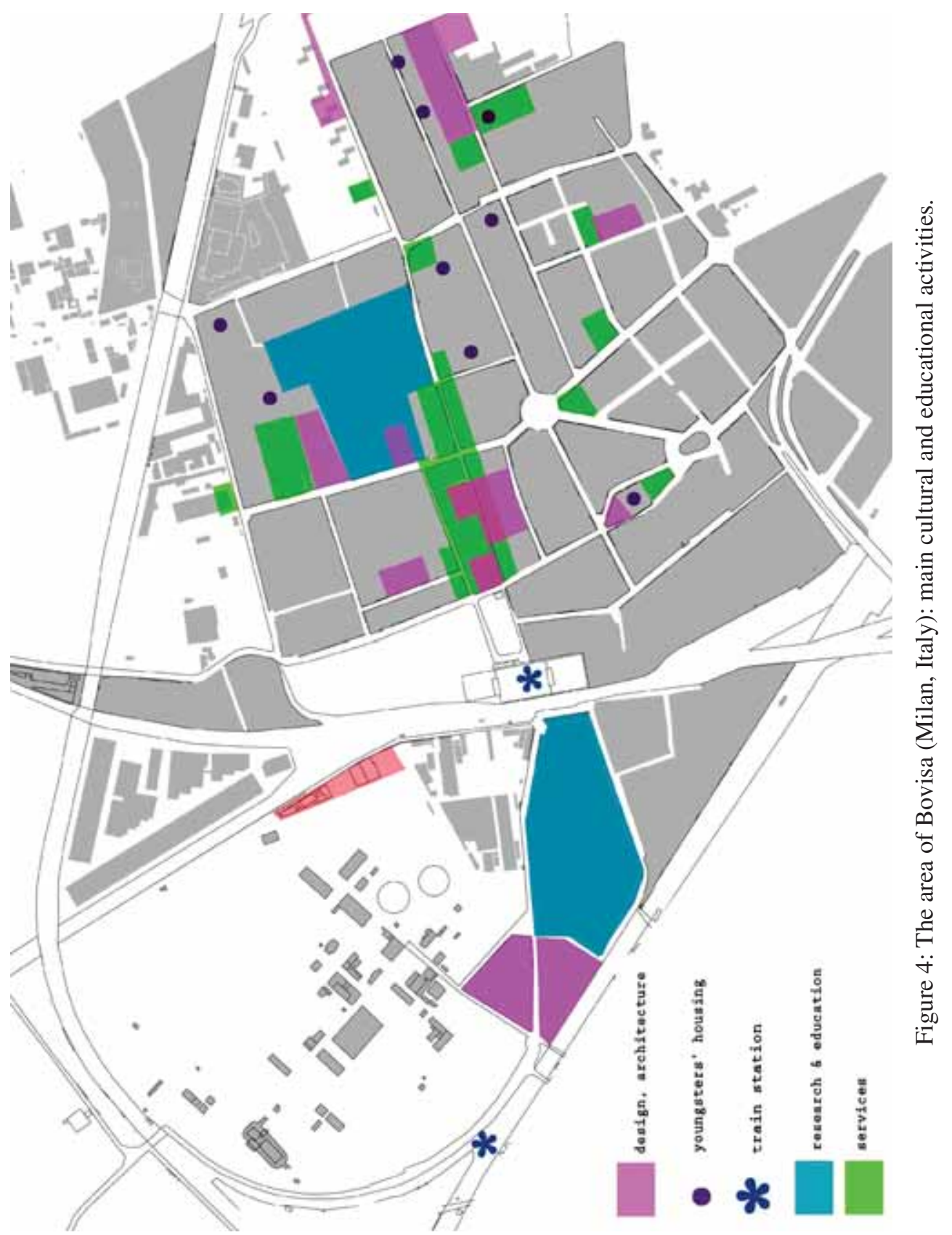




\section{GOALS OF THE PROJECT}

In this case, the preservation of the identity of a city and the creation of one of the largest cultural networks in Europe are the aims of the project. In addition, the urban and social development of a derelict area has to be considered as the mission of the proposal. We must point that this kind of approach is unique since cultural initiatives and new activities in Bovisa come and go because there is no solid network to support them, and investors do not attach any value to the industrial identity of the town. Due to this, the main goal of the research is to introduce new methodologies that can analyse, classify and plan the recovery of the neighbourhood protecting its industrial legacy. One valid tool can be the generation of mathematical models based on a multivariate analysis as a method for urban and cultural planning; this way it could be possible to define and evaluate a sustainable gentrification process. Further investigations following the same methodology will add new factors to classify and compare each zone according to the kind of factors chosen for each situation or requirement.

\section{CASE STUDY: ESTERNI'S NEW HEADQUARTERS AT BOVISA}

The project for esterni-Bovisa defines a multidisciplinary independent cultural centre with a policy focused on public space and its artistic improvement. The new cultural centre esterni-Bovisa will be based in a user-friendly building located in a former industrial structure where a high quality artistic program of regional and international significance with an awareness of contemporary culture ranging from design and contemporary art to architecture and cinema would be developed (Fig. 4).

Esterni is the artistic name for the management of the activities of Associazione Culturale Aprile, founded in 1995. The company has been active in Milan and other cities in Italy and abroad, since its foundation. They develop cultural projects in several fields like cinema, arts, design and music in collaboration with artists, architects, designers, university professors, etc. The upgrading of public areas and the centrality of people are the driving force of all esterni events. Their goals promote cultural exchange, integration and social responsibility. The city as a place where people meet and get together is the base for the development of all their activities.

Why to develop this project? Esterni-Bovisa will contribute to the improvement of the urban change of the Bovisa neighbourhood through the reuse of old industrial buildings. The ongoing projects of the area will regenerate a post-industrial suburb into a remarkable cultural and educational location in Milan. Nowadays, the area has become an important location for university activities as well as other cultural events, especially during fair trades in the city like the Milan Design Week. The possibility that esterni-Bovisa brings to its visitors will be the use of the space as an arts' production centre. The complex will include all kind of rental spaces for workshops, theatre/cinema, conference rooms, offices, ateliers, retail, exhibitions and temporary accommodation facilities.

Where? Esterni-Bovisa is located in a private street where the ex-Lavanna factory was carrying out its activities. The place is well connected to the airports and to the centre of Milan, the hinterland and the fair trades area by train - Bovisa Nord train station (on the East); Villapizzone trainstation (on the West); the metro (line 3) and by bus.

How to develop this business? The project for esterni in Bovisa is a cultural centre that reuses old industrial buildings transforming them in a heterogeneous complex for culture projects. The new esterni's headquarters will share their space with other rental spaces (Fig. 5). Those spaces will be available for anyone who wants to use them as a temporary office, atelier, workshops, conference rooms, urban orchards, local food restaurant, etc. The proposal includes as well an artists-in-residency programme in a multicultural exchange environment. Accommodation facilities will be available for esterni's collaborators and visitors. Industrial manufacturers that want to contribute to the construction process and become part of the community are invited to sponsor the project. 


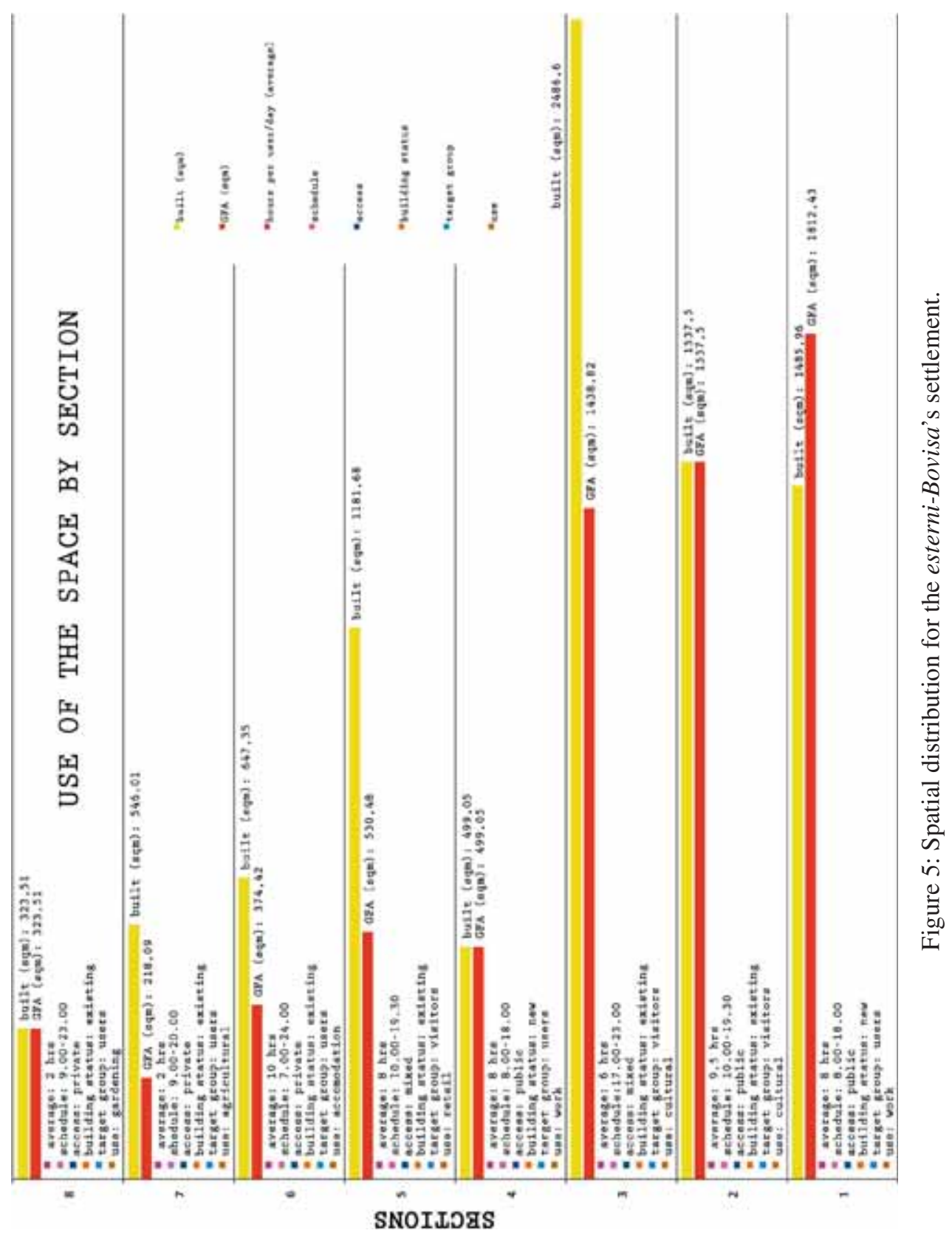



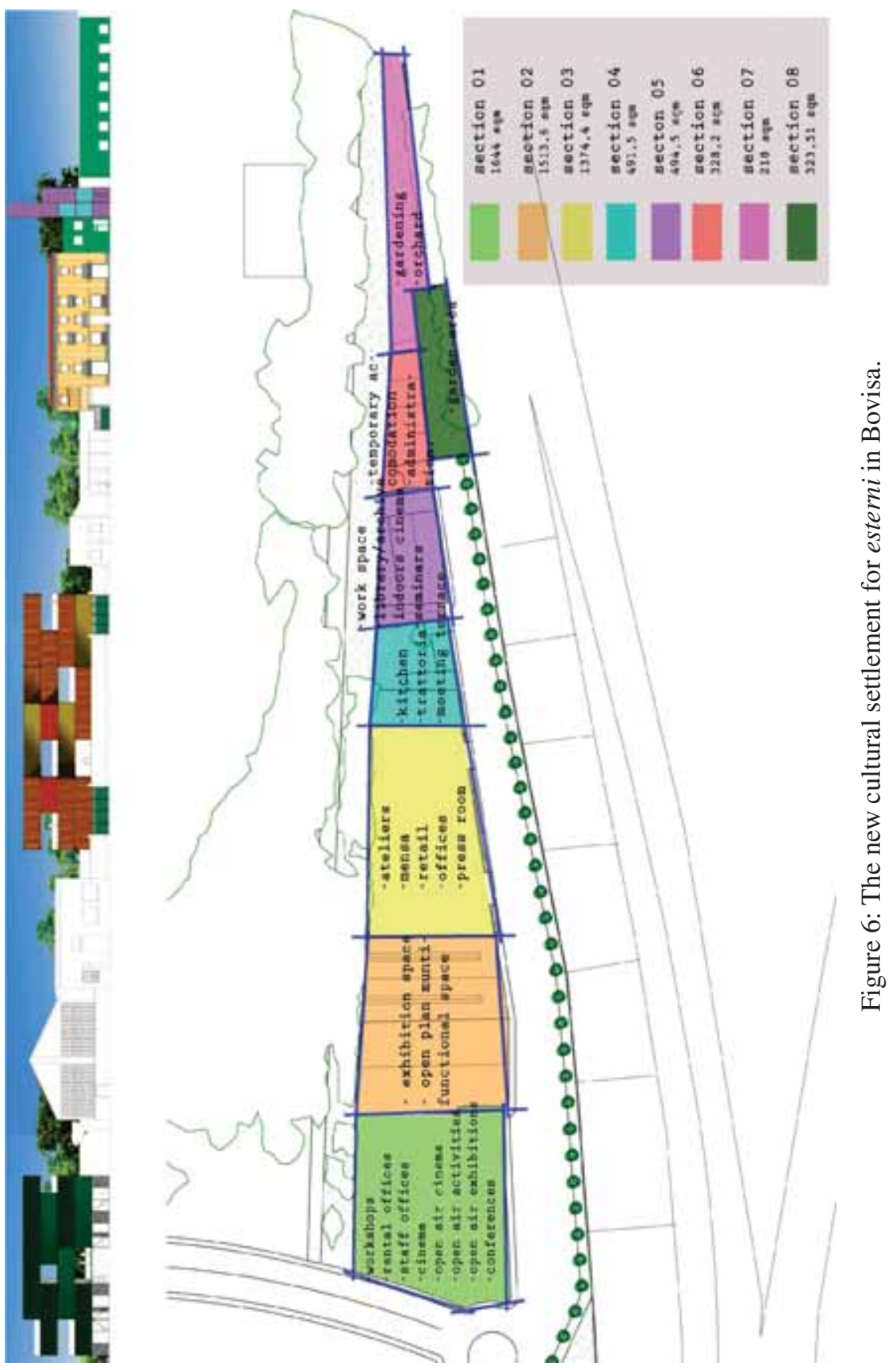


\section{VISION AND MISSION}

The new cultural settlement in Bovisa is part of a cultural planning strategy developed at an urban scale (Fig. 6). As one of the steps of the project, a marketing strategy has to be developed for the client, the investors, the sponsors and the users to become partners of the process. Following this, the aims of the new cultural centre are the improvement of mobility and professional development in Milan in the arts and crafts fields. Moreover, it is also aimed to make culture and arts accessible to everyone and give a value to the use of public spaces. From a social and environmental approach, the project focuses on the development of a sustainable architecture that recycles industrial manufacturers' encouraging the active participation of citizens, students and visitors in all the activities. The improvement of new ways of thinking and living in the city can be achieved through the creation of a cultural meeting point for young generations that will learn how to give a value to the use of public spaces, while interacting with people from other countries and facing international arts experiences from other associations.

Furthermore, the mission of this new cultural centre for esterni in Bovisa is the construction of a building in which all the events of esterni can be planned and developed. The use of the space as a location for arts and culture opened to everyone will contribute to the urban change of Bovisa through the adaptive reuse of old Milanese industrial areas. We look forward to a location where esterni will be able to provide temporary accommodation (artists-in-residency) and workshops for artists and emerging designers: a place where they can create, share their professional experiences and develop cultural events in Milan as part of the community of Bovisa.

\section{CONCLUSIONS}

Looking forward, for a sustainable development of the area of Bovisa and the recovery of its industrial archaeology, a strategy has been developed and defined according to the quality and quantity of the greenery, cultural life and industrial heritage of the whole area [2]. The goal of this project is the planning of an intervention at four parallel levels: architectonical, urban, social and cultural that will lead to a sustainable gentrification process. Some of the interventions that have been already done at the area of Bovisa have opened the way to this urban regeneration but there still exist a great number of industrial archaeology settlements to be preserved and transformed into a great cultural hub. The case study presented is an example of how this transformation can be continued. Here, the actors are a mid-size cultural association that share a common goal for the arts, culture, informal spaces and their social consequences at an urban level with large- and small-scale inhabitants of Bovisa.

\section{REFERENCES}

[1] Cognetti, Francesca. Bovisa in una goccia. Nuovi equilibri per un cuartiere in transformazione. Polipress: Politecnico di Milano, 1st edn June, 2007.

[2] Villacampa, Y. \& Villacampa, A., Re-use of the Industrial Heritage of Bovisa. A Model for Urban and Cultural Regeneration. University of Alicante: Spain; January, 2012.

[3] Oma. Bovisa Masterplan. Milan, Italy 2007, available at [on-line] http://www.oma.nl/[May $\left.26^{\text {th }} 2009\right]$.

[4] Sacramento, N. \& Zeiske, C., ARTocracy: Art, Informal Space and Social Consequence: A Curatorial Handbook in Collaborative Practice. Jovis Verlag GmbH: Berlin, 2010. 